\title{
Effectiveness of influenza vaccination programme in preventing hospital admissions, Valencia, 2014/15 early
} results

J Puig-Barberà (puig_joa@gva.es) ${ }^{1,2}$, A Mira-Iglesias' ${ }^{1}$ M Tortajada-Girbés³, F X López-Labrador ${ }^{1,4}$, A Belenguer-Varea ${ }^{5}$, M

Carballido-Fernández ${ }^{6}$, E Carbonell-Franco ${ }^{7}, C_{\text {Carratalá-Munuera }}^{8,9}$, R Limón-Ramírez $^{10}$, J Mollar-Maseres ${ }^{11}$,

M del Carmen Otero-Reigada ${ }^{11}$, G Schwarz-Chavarri ${ }^{12}$, J Tuells ${ }^{13}$, V Gil-Guillén 9,14 ,

for the Valencia Hospital Network for the Study of Influenza and Respiratory Viruses Disease ${ }^{15}$

1. Fundación para el Fomento de la Investigación Sanitaria y Biomédica de la Comunitat Valenciana (FISABIO), Valencia, Spain

2. Centro de Salud Pública de Castellón, Castellón, Spain

3. Hospital Doctor Peset, Valencia, Spain

4. Consorcio de Investigación Biomédica de Epidemiología y Salud Pública (CIBERESP), Instituto de Salud Carlos III, Madrid, Spain

5. Hospital de La Ribera, Alzira, Spain

6. Hospital General de Castellón, Spain

7. Hospital Arnau de Vilanova, Valencia, Spain

8. Hospital San Juan, Alicante, Spain

9. Cátedra de Medicina de Familia. Departamento de Medicina Clínica, Universidad Miguel Hernández, San Juan, Alicante, Spain

10. Hospital de la Plana, Vila-real, Spain

11. Hospital Universitario y Politécnico La Fe, Valencia, Spain

12. Hospital General de Alicante, Alicante, Spain

13. Hospital Universitario del Vinalopó, Elche, Spain

14. Hospital de Elda, Elda, Spain

15. The Valencia Hospital Network for the Study of Influenza and Respiratory Virus Disease (VAHNSI) members are listed at the end of the article

Citation style for this article:

Puig-Barberà J, Mira-Iglesias A, Tortajada-Girbés M, López-Labrador FX, Belenguer-Varea A, Carballido-Fernández M, Carbonell-Franco E, Carratalá-Munuera C, Limón-Ramírez R, Mollar-Maseres J, del Carmen Otero-Reigada M, Schwarz-Chavarri G, Tuells J, Gil-Guillén V, for the Valencia Hospital Network for the Study of Influenza and Respiratory Viruses Disease. Effectiveness of influenza vaccination programme in preventing hospital admissions, Valencia, $2014 / 15$ early results. Euro Surveill. 2015;20(8):pii=21044. Available online: http://www.eurosurveillance.org/ViewArticle.aspx?Articleld=21044

Preliminary results for the $2014 / 15$ season indicate low to null effect of vaccination against influenza $A\left(\mathrm{H}_{3} \mathrm{~N}_{2}\right)$ related disease. As of week 5 2015, there have been 1,136 hospital admissions, 210 were due to influenza and $98 \%$ of subtype A strains were $\mathrm{H}_{3}$. Adjusted influenza vaccine effectiveness was 33\% (range: 6-53\%) overall and $40 \%$ (range: $13 \%$ to $59 \%$ ) in those 65 years and older. Vaccination reduced by $44 \%(28-68 \%)$ the probability of admission with influenza.

\section{Introduction}

The 2014/15 influenza season in the northern hemisphere is characterised by the circulation of $\mathrm{A}\left(\mathrm{H}_{3} \mathrm{~N}_{2}\right)$ viruses belonging to clade $3 \mathrm{C} .2 \mathrm{a}$ and $3 \mathrm{C} .3 \mathrm{a}$, distinct from the $A / T e x a s / 50 / 2012\left(\mathrm{H}_{3} \mathrm{~N}_{2}\right)$-like (clade $3 \mathrm{C} .1$ ) reference strain used in the $2014 / 15$ northern hemisphere vaccine [1]. Preliminary influenza vaccine effectiveness (IVE) estimates from Canada [2,3] and Europe [4], report a null effect of the current vaccine in preventing laboratory-confirmed influenza $\mathrm{A}\left(\mathrm{H}_{3} \mathrm{~N}_{2}\right)$ with $3.4 \%$ (95\% confidence interval: ( -44.8 to 35.5$)$ against medically attended acute respiratory infection (ARI) and $-16.8 \%$ ( -48.9 to 8.3$)$ against hospital admissions. Early estimates from the United States (US) [5], reported a low effect of $23 \%(8-36 \%)$ against medically attended ARI associated with laboratory-confirmed influenza.

An active annual surveillance scheme in the Valencia Region in Spain monitors IVE in preventing laboratoryconfirmed influenza requiring hospitalisation [6]. In the current season, a split trivalent vaccine (Vaxigrip; SANOFI PASTEUR MSD, S.A. Madrid, Spain) was acquired by public tender and offered free of charge to non-institutionalised people targeted for influenza vaccination because of age or the presence of comorbidity [7].

We report 2014/15 influenza IVE in preventing laboratory-confirmed influenza admissions in patients admitted during the first eight weeks of the 2014/15 influenza season, from 7 December 2014 to 25 January 2015 .

\section{Methods}

We performed a test-negative study in 10 hospitals that provide healthcare to $48 \%$ of the $4,937,044$ inhabitants of Valencia. The influenza season began in week 502014 (Figure 1), as defined by two or more positive 
Hospital admissions with laboratory-confirmed influenza per week, Valencia, 7 December 2014-28 January 2015 $(\mathrm{n}=210)$

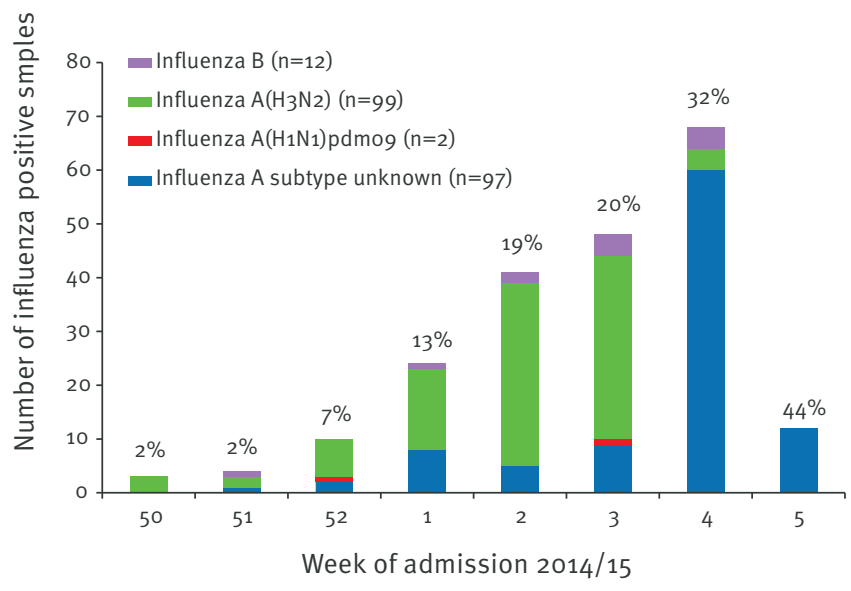

Numbers on top of bars: percentage of samples positive for influenza.

Source: Valencia Hospital Network for the Study of Influenza and Other Respiratory Viruses (VAHNSI).

influenza hospitalisations identified in two consecutive weeks.

Study procedures have been published [6]. Study staff screened emergency admissions for eligible subjects. Patients were included after written consent if they reported symptoms of influenza-like illness (ILI) [8] within seven days of admission. We collected a combined nasopharyngeal and pharyngeal flocked swab and sociodemographic and clinical information. A patient was considered immunised if they had received influenza vaccine more than 14 days before the onset of ILI (as recorded by the Vaccine Information System or by recall).

Laboratory confirmation was by semiquantitative reverse-transcription polymerase chain reaction. The specimens were tested in a centralised virology laboratory at Fundación para el Fomento de la Investigación Sanitaria y Biomédica (the Foundation for the Promotion of Health and Biomedical Research; FISABIO) following the World Health Organization (WHO) protocol [9].

Influenza-positive admissions were compared (vaccination odds ratio (OR)) with influenza-negative admissions $[10,11]$. Adjusted IVE was defined as $100 \mathrm{x}$ (1 - adjusted OR). We defined two groups for IVE estimation: (i) all subjects 18 years and older targeted for vaccination, and (ii) subjects aged 65 and older. Other subgroups were not considered to avoid a sparse-numbers bias $[2,12]$. The sample size sufficient to provide $80 \%$ statistical power to detect an IVE of at least $50 \%$, for a vaccine coverage of 50 to $60 \%$, with a delta of $10 \%$, was 130 to 150 influenza cases.
The adjusted OR were obtained by logistic regression. Previous knowledge and directed acyclic graphs (DAG) $[13,14]$ were used to define the variables finally used to improve comparability and exchangeability between vaccinated and non-vaccinated subjects and to clarify the minimum set of variables to be included in the regression logistics models and in the inverse probability-weighted regression adjustment models. The roles of 'previous vaccination' as an instrumental variable highly correlated with current vaccination and 'time to swab', which cannot be considered a confounder but is clearly related to outcome, were made explicit with the use of DAG. We assessed departure from linearity in categorical ordered variables, interaction between potential confounders and vaccination, and clustering by enrolment site or epidemiological week.

\section{FIGURE 2}

Flowchart showing exclusion criteria, study of mid-season influenza vaccine effectiveness in preventing hospital admissions related to influenza, Valencia, 7 December 2014-28 January 2015 ( $\mathrm{n}=3,988$ )

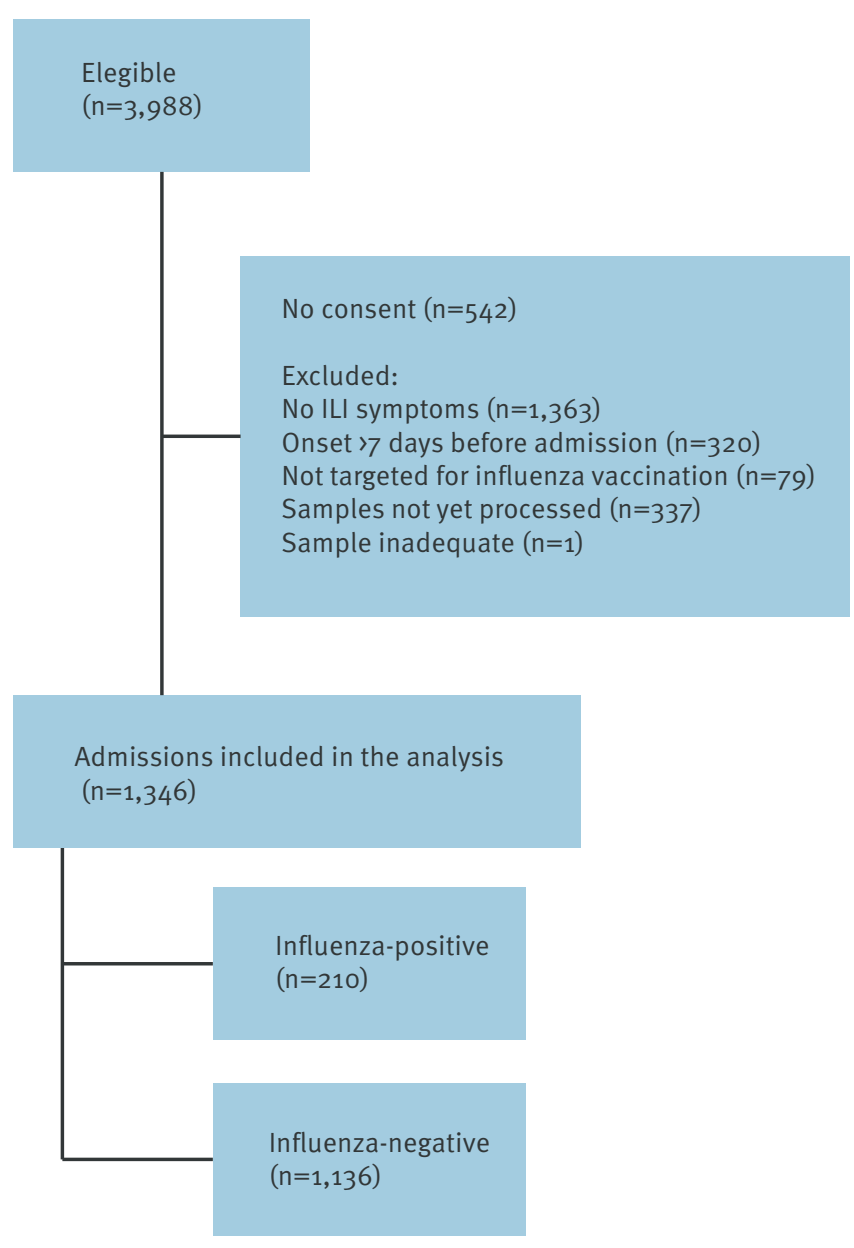

ILI: influenza-like illness.

Source: Valencia Hospital Network for the Study of Influenza. 
TABLE 1

Characteristics of included hospital admissions, Valencia, 7 December 2014-28 January $2015(\mathrm{n}=1,346)$

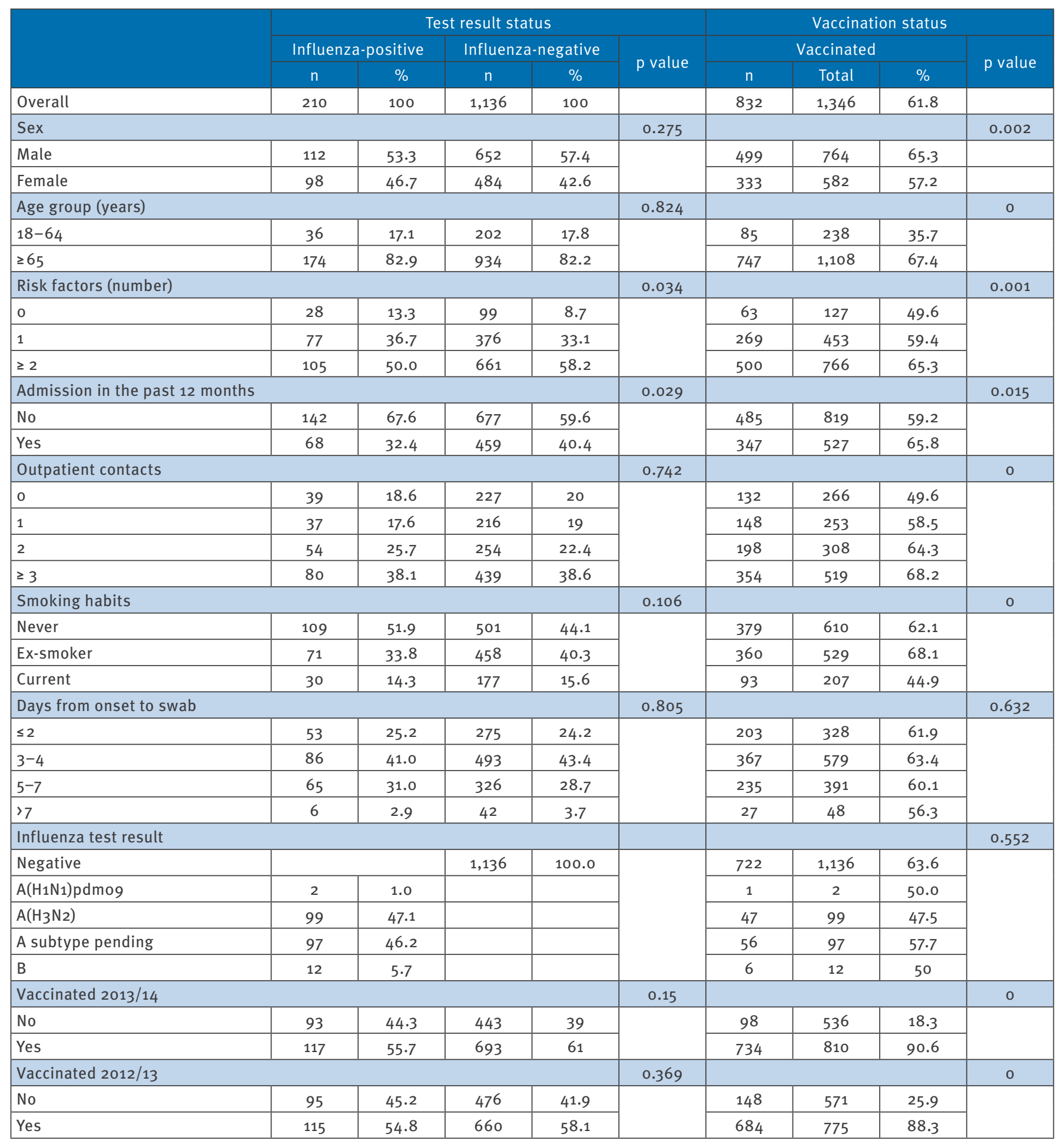

Source: Valencia Hospital Network for the Study of Influenza. 
Influenza vaccine effectiveness, preliminary results, Valencia, 7 December 2014-28 January $2015(\mathrm{n}=1,346)$

\begin{tabular}{|c|c|c|c|c|c|c|c|c|c|}
\hline & \multicolumn{3}{|c|}{ Influenza-positive } & \multicolumn{3}{|c|}{ Influenza-negative } & \multirow{3}{*}{ OR $(95 \% \mathrm{Cl})$} & \multirow{3}{*}{$\begin{array}{l}\text { Adjusted }^{a} \\
\text { OR }(95 \% \mathrm{Cl})\end{array}$} & \multirow{3}{*}{$\begin{array}{c}\operatorname{AVE}^{\mathrm{b}}(95 \% \\
\mathrm{CI})\end{array}$} \\
\hline & Vaccinated & Total sample & Vaccinated & Vaccinated & Total sample & Vaccinated & & & \\
\hline & $\mathrm{n}$ & $\mathrm{n}$ & $\%$ & $\mathrm{n}$ & $n$ & $\%$ & & & \\
\hline Overall & 110 & 210 & 52.4 & 722 & 1,136 & 63.6 & $\begin{array}{c}0.63 \\
(0.47-0.85) \\
\end{array}$ & $\begin{array}{c}0.67 \\
(0.47-0.94)\end{array}$ & $\begin{array}{c}44 \\
(28-60)\end{array}$ \\
\hline$\geq 65$ & 96 & 174 & 55.2 & 651 & 934 & 69.7 & $\begin{array}{c}0.53 \\
(0.38-0.74)\end{array}$ & $\begin{array}{c}0.60 \\
(0.41-0.87)\end{array}$ & $\begin{array}{c}48 \\
(32-64)\end{array}$ \\
\hline \multicolumn{10}{|c|}{ Swab ( $\leq 4$ days) } \\
\hline Overall & 78 & 139 & 56.1 & 492 & 768 & 64.1 & \begin{tabular}{|c|}
0.72 \\
$(0.50-1.04)$ \\
\end{tabular} & $\begin{array}{c}0.79 \\
(0.51-1.21) \\
\end{array}$ & $\begin{array}{c}32 \\
(11-53)\end{array}$ \\
\hline$\geq 65$ & 68 & 115 & 59.1 & 448 & 642 & 69.8 & $\begin{array}{c}0.62 \\
(0.41-0.94) \\
\end{array}$ & $\begin{array}{c}0.73 \\
(0.46-1.18) \\
\end{array}$ & $\begin{array}{c}32 \\
(9-55) \\
\end{array}$ \\
\hline \multicolumn{10}{|l|}{ VIS } \\
\hline Overall & 108 & 185 & 58.4 & 720 & 987 & 73.0 & $\begin{array}{c}0.52 \\
(0.38-0.72) \\
\end{array}$ & $\begin{array}{c}0.54 \\
(0.37-0.78) \\
\end{array}$ & $\begin{array}{c}49 \\
(34-63) \\
\end{array}$ \\
\hline$\geq 65$ & 95 & 157 & 60.5 & 649 & 838 & $77 \cdot 5$ & $\begin{array}{c}0.44 \\
(0.31-0.64) \\
\end{array}$ & $\begin{array}{c}0.49 \\
(0.33-0.74)\end{array}$ & $\begin{array}{c}50 \\
(35-66) \\
\end{array}$ \\
\hline \multicolumn{10}{|c|}{ VIS and Swabc } \\
\hline Overall & 76 & 120 & 63.3 & 490 & 677 & 72.4 & \begin{tabular}{|c|}
0.66 \\
$(0.44-0.99)$ \\
\end{tabular} & $\begin{array}{c}0.67 \\
(0.41-1.09) \\
\end{array}$ & $\begin{array}{c}37 \\
(17-57)\end{array}$ \\
\hline$\geq 65$ & 67 & 103 & 65.1 & 446 & 581 & 76.8 & $\begin{array}{c}0.56 \\
(0.36-0.88)\end{array}$ & $\begin{array}{c}0.62 \\
(0.36-1.05)\end{array}$ & $\begin{array}{c}37 \\
(15-59)\end{array}$ \\
\hline
\end{tabular}

AVE: average vaccination effect; $\mathrm{Cl}$ : confidence interval; OR: odds ratio; VIS: vaccine Information system.

a Adjusted by indicator variables: sex, age in deciles, smoking (never, ex-smoker, current smoker), number of outpatient contacts in the past three months $(0,1,2,>2)$, number of comorbidities $(0,1,2, \geq 2)$, hospital admissions in the past 12 months (yes, no), recruitment hospital, epidemiological week of admission, days from onset of symptoms to swab $(\leq 2,3-4,5-7,>7)$.

${ }^{b}$ Average vaccination effect (percentage of reduction) on the probability of admission with confirmed influenza. Admission with influenza was conditioned on age in deciles, smoking (never, ex-smoker, current smoker), number of outpatient contacts in the past three months (o, $1,2,>2)$, number of comorbidities $(0,1,2, \geq 2)$, hospital admissions in the past 12 months (yes, no), recruitment hospital, epidemiological week of admission, days from onset of symptoms to swab $(\leq 2,3-4,5-7,>7)$. Vaccination was conditioned on the same indicator variables, but days to swab was omitted and record of influenza vaccination in 2012 and 2013 were added to the model.

c Patients included are those with records of any vaccination in the VIS and swabbed $\leq 4$ days after symptoms onset.

Source: Valencia Hospital Network for the Study of Influenza.

We used inverse probability-weighted regression adjustment to estimate the vaccination average effect from observed data $[15,16]$ after conditioning influenza admissions on indicator variables: age in deciles, epidemiological week, number of comorbidities, smoking habits, hospital admission in the last 12 months, number of outpatient contacts in the last three months, time to swab, and recruitment hospital. We conditioned vaccination on the same covariates, excluding time to swab and adding influenza vaccination in the past two seasons.

Sensitivity analyses were performed according to time to swab and vaccination ascertainment in the vaccine information system. All probabilities were two-tailed; $p<0.05$ was considered significant. Analyses were performed with Stata 13.1 (StataCorp, College Station, TX).

The Ethics Research Committee of the Dirección General de Salud Pública-Centro Superior de Investigación en Salud Pública (DGSP-CSISP) approved the protocol of the study.

\section{Results}

We enrolled 1,136 hospital admissions, 210 with influenza (Figure 2), 196 of them influenza A. Of the 101 influenza A subtyped strains, 99 (98\%) were $\mathrm{H}_{3}$. Of all admissions, 1,108 (82\%) were patients older than 65 years (Table 1). Of the 210 influenza-positive patients, $110(52 \%)$ were vaccinated compared with $722(64 \%)$ of 1,136 influenza-negative patients (Table 2 ).

Adjusted IVE was 33\% (6-53\%) overall and 40\% (13$59 \%$ ) in those 65 years and older (Table 2). The probability of influenza-related admission in vaccinated individuals was $13 \%(10-15 \%)$ compared with $22 \%$ $(18-27 \%)$ in those unvaccinated (data not shown). Vaccination reduced by $44 \%(28-68 \%)$ the overall probability of hospital admission with influenza (Table 2). These results were not altered in the sensitivity analysis (Table 2 ).

\section{Discussion}

Our estimate suggests that the 2014/15 influenza vaccine was moderately effective in preventing hospital admissions related to influenza in a season in which 
most influenza $\mathrm{A}\left(\mathrm{H}_{3} \mathrm{~N}_{2}\right)$ viruses were different from the component in the 2014/15 influenza vaccine [17]. We can only provide information regarding the genetic characteristics of strains analysed at the Centro Nacional de Microbiología, Instituto de Salud Carlos III in Madrid [17]. According to their data, $67 \%$ of $A\left(\mathrm{H}_{3} \mathrm{~N}_{2}\right)$ clades could be considered antigenically and genetically different from the vaccine strain. We cannot make inferences regarding the impact on IVE of the type of vaccine used in Valencia as only one brand of vaccine was used throughout the region ( $99 \%$ of doses according to the vaccination registry).

Previous reviews and reports have shown that the trivalent inactivated vaccine can confer substantial protection against mismatched influenza $A$ [18-20]. Unfortunately, data from mismatched seasons on IVE in people 65 years and older are scarce [21].

There can be considerable variation in reported IVE estimates due to differences in strain circulation among countries, strain proportion within one region, the vaccines used, age-specific vaccine coverage, the population studied, season definition, case definition, ascertainment of vaccination status, differences in the period of surveillance, the variables included or omitted in the statistical model, how they are modelled, and measured outcome (admission, outpatient contact or infection) [11]. A major caveat are sparse numbers. The absence of statistical significance should be expected in studies with low vaccine coverage, IVE or a limited sample size $[2,12]$, as reflected in our sensitivity analysis (Table 2 ).

Influenza VE estimates generated from surveillance data using the test-negative design have already been presented at the WHO's annual strain selection meeting [11] as a way to improve the vaccine composition. However, variation in the estimates may undermine their credibility and usefulness, particularly early in the season. It is important to focus on sufficient sample size, robustness of the design, representativeness of the population, and validity of adjustment to inform vaccine reformulation and vaccination policies based on epidemiological data.

Our results support the substantial benefit of vaccination in preventing hospital admissions with laboratoryconfirmed influenza in the first weeks of the 2014/15 season in Valencia.

\section{Acknowledgements}

The authors thank the staff of Hospital General de Castello in Castellón; La Plana, in Vila-real; Arnau de Vilanova, in Valencia; La Fe, in Valencia; Hospital Dr Peset, in Valencia; Hospital La Ribera, in Alzira; Hospital San Juan, in Alicante; Hospital General de Alicante, in Alicante; Hospital de Elda, in Elda and Hospital del Vinalopó, in Elx, for their support. We thank all the study participants and their families.

\section{Conflict of interest}

The study was funded by a contract between FISABIO and Sanofi-Pasteur. SanofiPasteur did not participate in the design, conduct of the study, analysis or decision to publish the study.

\section{Authors' contributions}

JPB: study coordinator, data analysis and draft of the manuscript; AMI: data management and data analysis; XLL: molecular analysis; MTG, ABV, MCF, ECF, CCM, RLR, JMM, MOR, GSC, JTH and VGG: investigators. Critical review and approval of the manuscript: all

Members of the Valencia Hospital Network for the Study of Influenza and Respiratory Virus Disease (VAHNSI)

Main contact: Joan Puig-Barberà (puig_joa@gva.es). Group members: Ángel Belenguer-Varea, Hospital de La Ribera, Alzira, Spain. Mario Carballido, Hospital General de Castellón, Castellón, Spain. Empar Carbonell-Franco, Hospital Arnau de Vilanova, Valencia, Spain. Concha Carratalá-Munuera, Hospital San Juan de Alicante, Alicante, Spain. Vicente Gil-Guillén,Hospital de Elda, Elda, Spain. Ramón Limón-Ramírez, Hospital La Plana, Vila-real, Spain. Joan Mollar-Maseres, Hospital La Fe, Valencia, Spain. Maria del Carmen Otero-Reigada, Hospital la Fe, Valencia, Spain. Germán Schwarz-Chavarri, Hospital General de Alicante, Spain. Miguel Tortajada-Girbés, Hospital Dr. Peset, Valencia, Spain. Javier-Diez-Domingo, FISABIO, Valencia, Spain. Xavier López-Labrador, FISABIO, Valencia, Spain. Angels Natividad-Sancho, FISABIO, Valencia, Spain. Ainara MiraIglesias, FISABIO, Valencia, Spain. Amparo Buigues-Vila, FISABIO, Valencia, Spain. Begoña Escribano-López, FISABIO, Valencia, Spain.

\section{References}

1. World Health Organization (WHO). Influenza Update $\mathrm{N}^{\circ} 230.9$ February 2015, based on data up to 25 January 2015. Geneva: WHO; 9 February 2015. Available from: http://www.who.int/ influenza/surveillance_monitoring/updates/2015_02_09_ surveillance_update_230.pdf?ua=1

2. Skowronski D, Chambers C, Sabaiduc S, De Serres G, Dickinson J, Winter A, et al. Interim estimates of 2014/15 vaccine effectiveness against influenza $\mathrm{A}\left(\mathrm{H}_{3} \mathrm{~N}_{2}\right)$ from $\mathrm{Canada}$ S Sentinel Physician Surveillance Network, January 2015. Euro Surveill. 2015;20(4):21022. http://dx.doi.org/10.2807/15607917.ES2015.20.4.21022 PMID:25655053

3. McNeil S, Andrew M, Ye L, Haguinet F, Hatchette T, ElSherif $M$, et al.; Investigators of the Serious Outcomes Surveillance Network of the Canadian Immunization Research Network (CIRN). Interim estimates of 2014/15 influenza vaccine effectiveness in preventing laboratory-confirmed influenzarelated hospitalisation from the Serious Outcomes Surveillance Network of the Canadian Immunization Research Network, January 2015. Euro Surveill. 2015;20(5):21024. http://dx.doi. org/10.2807/1560-7917.ES2015.20.5.21024 PMID:25677052

4. Pebody R, Warburton F, Ellis J, Andrews N, Thompson C, von Wissmann B, et al. Low effectiveness of seasonal influenza vaccine in preventing laboratory-confirmed influenza in primary care in the United Kingdom: 2014/15 mid-season results. Euro Surveill. 2015;20(5):21025. http://dx.doi. org/10.2807/1560-7917.ES2015.20.5.21025 PMID:25677050

5. Flannery B, Clippard J, Zimmerman RK, Nowalk MP, Jackson ML, Jackson LA, et al. Early estimates of seasonal influenza vaccine effectiveness - United States, january 2015. MMWR Morb Mortal Wkly Rep. 2015;64(1):10-5. PMID:25590680

6. Puig-Barberà J, García-de-Lomas J, Díez-Domingo J, ArnedoPena A, Ruiz-García M, Limón-Ramírez R, et al.; Valencia Hospital Network for the Study of Influenza and Respiratory Virus Disease. Influenza vaccine effectiveness in preventing influenza $\mathrm{A}\left(\mathrm{H}_{3} \mathrm{~N}_{2}\right)$-related hospitalizations in adults targeted for vaccination by type of vaccine: a hospital-based testnegative study, 2011-2012 $\mathrm{A}\left(\mathrm{H}_{3} \mathrm{~N}_{2}\right)$ predominant influenza 
season, Valencia, Spain. PLoS ONE. 2014;9(11):e112294. http:// dx.doi.org/10.1371/journal.pone.0112294 PMID:25392931

7. La gripe. [Influenza]. Madrid: Ministerio de Sanidad. [Accessed 25 Feb 2015]. Spanish. Available from: https://www.msssi. gob.es/ciudadanos/enfLesiones/enfTransmisibles/gripe/gripe. htm\#Prev1

8. European Influenza Surveillance Network (EISN). Influenza case definitions. Clinical criteria. Influenza-like illness (ILI). Stockholm: European Centre for Disease Prevention and Control (ECDC). [Accessed: 2 Nov 2012]. Available from: http:// ecdc.europa.eu/en/activities/surveillance/EISN/surveillance/ Pages/influenza_case_definitions.aspx

9. World Health Organization (WHO). WHO information for molecular diagnosis of influenza virus in humans - update. Geneva: WHO; November 2012. Available from: http://www. who.int/influenza/gisrs_laboratory/molecular_diagnosis_ influenza_virus_humans_update_201211.pdf

10. Jackson ML, Nelson JC. The test-negative design for estimating influenza vaccine effectiveness. Vaccine. 2013;31(17):21658. http://dx.doi.org/10.1016/j.vaccine.2013.02.053 PMID:23499601

11. Sullivan SG, Feng S, Cowling BJ. Potential of the test-negative design for measuring influenza vaccine effectiveness: a systematic review. Expert Rev Vaccines. 2014;13(12):157191. http://dx.doi.org/10.1586/14760584.2014.966695 PMID:25348015

12. Ellis PD. The essential guide to effect sizes: statistical power, meta-analysis, and the interpretation of research results. Cambridge; New York: Cambridge University Press; 2010.

13. Pearl J. Causal diagrams for empirical research. Biometrika. 1995;82(4):669-88. http://dx.doi.org/10.1093/ biomet/82.4.669

14. Greenland S, Pearl J, Robins JM. Causal diagrams for epidemiologic research. Epidemiology. 1999;10(1):37-48. http://dx.doi.org/10.1097/00001648-199901000-00008 PMID:9888278

15. Rubin DB. Estimating causal effects of treatments in randomized and nonrandomized studies. J Educ Psychol. 1974;66(5):688-701. http://dx.doi.org/10.1037/ho037350

16. Cole SR, Hernán MA. Constructing inverse probability weights for marginal structural models. Am J Epidemiol. 2008;168(6):656-64. http://dx.doi.org/10.1093/aje/kwn164 PMID:18682488

17. Informe semanal de vigilancia de la gripe en España. Semana 06/2015. [Weekly surveillance report on influenza in Spain. Week 06/2015]. No 422. Madrid: Instituto de Salud Carlos III; 12 Feb 2015. Spanish. Available from: http://www.isciii. es/ISCIII/es/contenidos/fd-servicios-cientifico-tecnicos/fdvigilancias-alertas/fd-enfermedades/fd-gripe/grno62015.pdf

18. Jefferson TO, Rivetti D, Di Pietrantonj C, Rivetti A, Demicheli V. Vaccines for preventing influenza in healthy adults. Cochrane Database Syst Rev. 2007; (2):CDo01269. PMID:17443504

19. Tricco AC, Chit A, Soobiah C, Hallett D, Meier G, Chen MH, et al. Comparing influenza vaccine efficacy against mismatched and matched strains: a systematic review and meta-analysis. BMC Med. 2013;11(1):153. http://dx.doi.org/10.1186/1741-7015-11-153 PMID:23800265

20. Kelly HA, Sullivan SG, Grant KA, Fielding JE. Moderate influenza vaccine effectiveness with variable effectiveness by match between circulating and vaccine strains in Australian adults aged 20-64 years, 2007-2011. Influenza Other Respi Viruses. 2013;7(5):729-37. http://dx.doi.org/10.1111/irv.12018 PMID:23078073

21. Osterholm MT, Kelley NS, Sommer A, Belongia EA. Efficacy and effectiveness of influenza vaccines: a systematic review and meta-analysis. Lancet Infect Dis. 2012;12(1):36-44. http:// dx.doi.org/10.1016/S1473-3099(11)70295-X PMID:22032844 